This item was submitted to Loughborough's Research Repository by the author.

Items in Figshare are protected by copyright, with all rights reserved, unless otherwise indicated.

\title{
Immediate pre-meal water ingestion decreases voluntary food intake in lean young males
}

\section{PLEASE CITE THE PUBLISHED VERSION}

http://dx.doi.org/10.1007/s00394-015-0903-4

\section{PUBLISHER}

(C) Springer

VERSION

AM (Accepted Manuscript)

\section{PUBLISHER STATEMENT}

This work is made available according to the conditions of the Creative Commons Attribution-NonCommercialNoDerivatives 4.0 International (CC BY-NC-ND 4.0) licence. Full details of this licence are available at: https://creativecommons.org/licenses/by-nc-nd/4.0/

\section{LICENCE}

CC BY-NC-ND 4.0

\section{REPOSITORY RECORD}

Corney, Robert A., Caroline Sunderland, and Lewis J. James. 2019. "Immediate Pre-meal Water Ingestion Decreases Voluntary Food Intake in Lean Young Males”. figshare. https://hdl.handle.net/2134/20838. 
1 Immediate pre-meal water ingestion decreases voluntary food intake in lean young males

2

3 Robert A. Corney ${ }^{\mathrm{a}}$, Caroline Sunderland ${ }^{\mathrm{b}}$, Lewis J. James ${ }^{\mathrm{a}}$

$4 \quad{ }^{a}$ School of Sport, Exercise and Health Sciences, Loughborough University, Leicestershire, UK, LE11

5 3TU.

$6 \quad$ b School of Science and Technology, Nottingham Trent University, Nottingham, NG11 8NS.

7

8 Key words

9 Appetite; Preload; Fluid; Weight Management; Hydration

10

11

12 Corresponding author

13 Lewis J. James

14 L.james@lboro.ac.uk

15 School of Sport, Exercise and Health Sciences

16 Loughborough University

17

18

19

20

21

22

23

24

25 
Purpose: Consuming 375-500 $\mathrm{ml}$ of water $30 \mathrm{~min}$ before a meal has been shown to reduce energy intake in older, but not younger adults. This study investigated the effects of ingesting a water preload immediately pre-meal ( $<1$ min before eating) on within-meal ad-libitum energy intake in non-obese young males.

31 Methods: Fourteen healthy males (mean (SD) age 27 (3) y, Height 1.83 (0.05) m, body weight 80.47 32 (9.89) kg, body fat $17.5(4.0) \%$, body mass index $\left.24.0(2.5) \mathrm{kg} / \mathrm{m}^{2}\right)$ completed a familiarisation trial and two experimental trials in randomised counterbalanced order. Subjects arrived at the laboratory overnight fasted and consumed an ad-libitum porridge breakfast. Immediately prior to the meal, subjects consumed either a $568 \mathrm{ml}$ (1 pint) water preload (preload trial) or no preload (control trial). Visual analogue scale questionnaires to assess hunger, fullness and satisfaction were completed before and after the meal in both trials, as well as after the water preload. Results: Ad-libitum energy intake was greater $(\mathrm{P}<0.001)$ during control $(2551(562) \mathrm{kJ})$ than preload (1967 (454) kJ). Ad-libitum water intake was also greater $(\mathrm{P}<0.001)$ during control (318 (226-975) ml) than preload (116 (0-581) $\mathrm{ml})$. The water preload increased fullness and satisfaction and decreased hunger compared to pre-trial $(\mathrm{P}<0.001)$ and the control trial $(\mathrm{P}<0.001)$. a meal reduces energy intake in non-obese young males. This might therefore be an effective strategy to suppress energy intake in this population and possibly assist with weight management.

45 


\section{Introduction}

The global prevalence of obesity and its co-morbidities means that there is a growing need to identify strategies to facilitate appropriate energy balance. In overweight and obese populations, strategies that promote a negative energy balance and subsequent weight loss might be required. However, to prevent the continued rise in obesity prevalence, interventions that attenuate or prevent a positive energy balance and weight gain among healthy weight individuals might also be important [1]. Whilst much research has focused on the effects of the energy containing macronutrients on energy balance [2-4] more recent evidence suggests water might play an important role in facilitating weight management [5]. Consistent with this, a recent systematic review [6] concluded that increased water consumption in combination with a program for weight maintenance/ weight loss, reduced body weight to a greater extent than the program alone.

A number of studies have investigated the effects of ingesting water before a meal on subsequent voluntary food intake [7-9]. Studies have reported that ingestion of a water preload 30 minutes before an ad-libitum meal leads to a reduction in energy intake at the meal in non-obese older [8] and obese older adults [9], but not younger adults [7, 8]. The mechanism by which water ingestion before a meal reduces acute energy intake is not fully understood, but might be related to increased gastric distention, producing increased feelings of satiety and decreased hunger. In line with this, data from animal studies suggests that increased gastric distension reduces energy intake [10], possibly via activation of gastric stretch receptors [11]. The provision of water 30 minutes before a meal allows time for the water to empty from the stomach, which will reduce the amount of gastric distention present at the onset of feeding. Given that the rate of gastric emptying for liquid meals is slower in older vs. younger adults [12], reducing the time between preload ingestion and feeding in young adults might increase gastric distention during feeding and reduce ad-libitum food intake.

Therefore the purpose of the current study was to investigate the effects of a water preload consumed immediately before an ad-libitum meal on subjective appetite sensations and energy intake. The preload was consumed immediately pre-meal to maximise its impact on gastric distension. It was 
83 hypothesised that pre-meal water ingestion would suppress appetite and energy intake compared to a

84 no preload control trial.

85

Methods

87

Subjects

Fourteen healthy, lean males with age 27 (3) y, height 1.83 (0.05) m, body weight 80.47 (9.89) kg, body fat 17.5 (4.0) \%, body mass index $24.0(2.5) \mathrm{kg} \cdot \mathrm{m}^{-2}$ volunteered for this study, which was approved by the University's Ethical Advisory Committee. Subjects were habitual breakfast consumers, non-smokers and had not been on any weight loss/ gain diet during the previous 6 months. Subjects completed a health-screening questionnaire, a three factor-eating questionnaire [13] and provided written consent. G*Power 3.1.6 [14] and unpublished data from our laboratory using the same porridge breakfast with a between trial correlation of 0.83 was used to estimate the required sample size. We estimated an expected difference between trials of $\sim 420 \mathrm{~kJ}$, and using an $\alpha$ of 0.05 and statistical power of 0.8 , it was determined that 11 subjects would be required to reject the null hypothesis.

Each subject completed a familiarisation trial followed by two experimental trials in a randomised, counterbalanced fashion, separated by $\geq 7$ days. In the $24 \mathrm{~h}$ before the first experimental trial subjects weighed and recorded all dietary intake and recorded any habitual physical activity in a diary. They then replicated these diet and activity patterns in the $24 \mathrm{~h}$ preceding the second experimental trial. Subjects refrained from any strenuous physical activity, alcohol intake and dietary supplementation during the $24 \mathrm{~h}$ pre-trial.

106

107 During the familiarisation trial subjects arrived overnight fasted $(\sim 10 \mathrm{~h})$ and after voiding, their body weight (in underwear) (Adam CFW 150 scale; Adam Equipment Co Ltd, Milton Keynes, UK) and

109 height (Stadiometer, Seca Ltd, Germany) were measured. Subcutaneous skinfold measurements were obtained from the triceps, biceps, subscapular and suprailiac, and subsequently body fat percentage

111 was estimated using the Siri equation [15]. Subjects then selected their preferred flavour (plain, 
112 golden syrup or chocolate) of porridge (Ready Brek, Weetabix, Kettering, UK made with semi-

113 skimmed milk) and were familiarised with the ad-libitum meal as described for the control trial. They

114 consumed their preferred flavour of porridge for the familiarisation trial and both experimental trials.

115

116

117

118

119

Experimental trials began overnight fasted $(\sim 10 \mathrm{~h})$ and at a time typical for each subject to consume breakfast (7-10 am). Subjects voided before body weight (in underwear) was measured. Subjects then entered a custom built feeding booth within an isolated laboratory and ingested either 568 ml water (preload trial) or no water (control trial), before being provided with the ad-libitum breakfast meal. The time it took for subjects to consume the water preload was recorded, with subjects consuming the water in 13 (5) s (range 7-21 s). Subjects were provided with a bowl of porridge (90 g dry porridge oats: $420 \mathrm{ml}$ semi-skimmed milk) and a glass of water. Once $1 / 2$ to $3 / 4$ of the bowl had been consumed, it was replaced with a fresh bowl of porridge and this process continued until subjects indicated satiation. Similarly, the drinking water was replaced when required. New bowls of porridge were provided at times determined during familiarisation and specific to the speed of consumption of each subject (approximately every 3-6 min). This ensured that warm food was always available and that finishing a bowl did not act as a cue to stop eating. Subjects were instructed to eat until they were 'comfortably full and satisfied' and to indicate satiation by leaving the feeding booth and sitting in the adjoining laboratory. Subjects had a total time of 30 min in which to eat and remained in the laboratory in isolation for the entire $30 \mathrm{~min}$. Warm food was continuously available throughout the 30 min and once they had left the feeding booth subjects could return and continue eating if they desired, although none did. All subjects had terminated eating within the 30 min. Energy intake was quantified using manufacturer values and by weighing the porridge before and after heating and cooling, as well as before and after the ad-libitum meal.

Subjects completed $100 \mathrm{~mm}$ visual analogue scale questionnaires [16] for hunger: "how hungry do you feel?”, fullness: “how full do you feel?” and satisfaction: "how satisfied do you feel?” after body weight measurement (pre-trial), after the preload in the preload trial (post-drink) and after the 30 min feeding period (post-trial). Verbal anchors “not at all” and “extremely” were placed at 0 and $100 \mathrm{~mm}$, respectively. 

Statistical Analysis

144 distribution using a Shapiro Wilk test. Subjective appetite perceptions were analysed using two way repeated measures ANOVA, followed by Bonferroni adjusted Wilcoxon signed rank tests. For the purposes of statistical analysis, post-drink appetite perceptions were assumed to be the same as the

$148<30 \mathrm{~s}$ apart during the preload trial. Food and water intake data were analysed using t-tests or 149 Wilcoxon Signed Rank tests, as appropriate. Normally distributed data are presented as mean (SD), 150 whilst non-normally distributed data are presented as median (range). Differences were accepted as 151 being significant when $P<0.05$.

\section{Results}

154 Pre-trial

155 Pre-trial body weight was similar for the preload (81.08 (9.69) kg) and control (81.33 (9.49) kg) trials 156 ( $P=0.117)$. Subjective appetite perceptions of fullness $(P=0.103)$, hunger $(P=0.168)$ and satisfaction $(P=0.965)$ were also not different between trials.

158

\section{Ad-libitum Meal}

160 Energy intake at the ad-libitum meal was 1967 (454) kJ (preload) and 2551 (562) kJ (control) 161 ( $P<0.001$; Fig 1), a difference of 22 (14) \%. There was no trial order effect, with similar energy 162 intake during the first (2213 (633) kJ) and second (2305 (547) kJ) experimental trials $(P=0.658)$. 163 Water ingestion during the ad-libitum meal was also reduced during preload (116 (0-581) $\mathrm{ml})$ 164 compared to control (318 (226-975) $\mathrm{ml})(P<0.001)$, although including the $568 \mathrm{ml}$ water ingested 165 immediately pre-meal during preload, total water intake was greater during preload (684 (568-1149) $166 \mathrm{ml})(P<0.001)$.

\section{Subjective appetite perceptions}

169 There were interaction effects for fullness, hunger and satisfaction $(\mathrm{P}<0.001)$ (Table 1$)$. At post-drink, 170 fullness and satisfaction were greater and hunger lower during preload than during control $(\mathrm{P}<0.001)$. 
171 Compared to pre-trial, fullness and satisfaction were increased and hunger decreased at post-trial during both trials $(\mathrm{P}<0.001)$, as well as at post-drink during preload $(\mathrm{P}<0.001)$.

173

174

175

176

\section{Discussion}

This study examined the effect of immediate pre-meal water ingestion on acute ad-libitum energy intake. The main finding was that consumption of $568 \mathrm{ml}$ (1 pint) of water immediately before breakfast reduced ad-libitum energy intake at the breakfast by 22\%. Furthermore, subjective feelings of hunger were decreased, whilst fullness and satisfaction were increased immediately after the water preload.

A number of previous studies have investigated the effect of pre-meal water ingestion on ad-libitum energy intake at a single meal [7-9], with water ingested either $30 \mathrm{~min}$ or $60 \mathrm{~min}$ before the adlibitum meal. Studies of obese [9] and non-obese [8] older adults ( 60 y of age) have reported that a water preload ingested 30 minutes before a meal, reduces ad-libitum energy intake at the meal compared to a no preload trial. In contrast, studies of young adults have observed no effect on adlibitum energy intake compared to a no preload control trial when water preloads are provided 30 minutes before a meal [7, 8], 60 minutes before a meal [7] or during a meal [7].

What accounts for the divergent responses of young and old to a water preload ingested 30 min before feeding is not clear, but Van Walleghen et al. [8] suggest it might be related to differences in gastric emptying rates. Indeed, Clarkston et al. [12] demonstrated that gastric emptying of both liquids and solids is delayed by $\sim 26 \%$ and $30 \%$, respectively, in old compared to young subjects. The gastric emptying rate of a liquid is linearly related to the energy density of the liquid [17], with more energy dense liquids emptying from the stomach more slowly. Consequently, water empties from the stomach very rapidly and Vist and Maughan [18] reported that 30 min after ingesting $600 \mathrm{ml}$ water, only $44 \mathrm{ml}$ remained in the stomach of a group of young (21-44 y) males. Therefore a water preload ingested 30 min prior to an ad-libitum meal will be almost completely emptied from the stomach by the time of the meal, at least in healthy young populations, and thus is unlikely to influence $a d-$ libitum energy intake. 
202 The current study was designed to maximise feelings of gastric distention during feeding, and as such 203 the water preload was provided immediately before the ad-libitum meal. The results of this study 204 contrast with these previous studies in young populations [7, 8] and suggest that the preload-to-meal 205 time interval might be an important consideration for the efficacy of a water preload in reducing acute energy intake. Research on energy containing preloads suggests that a preload-to-meal time interval 207 of 30 minutes is optimal for maximising the impact of a preload on acute ad-libitum energy intake

208 [19]. However, the mechanism by which an energy containing preload impacts ad-libitum energy 209 intake is unlikely to be the same as for water. Therefore, the optimal time interval between preload 210 ingestion and feeding is unlikely to be the same for energy-containing and energy-free preloads. The 211 present study only tested one volume of preload (i.e. $568 \mathrm{ml}$ ) and one preload-to-meal time interval 212 (i.e. immediately pre-meal). Future studies should manipulate the preload volume and preload-to213 meal time interval to maximise the impact on energy intake.

215 The most plausible explanation by which pre-meal water intake reduced ad-libitum energy intake is 216 likely to be gastric distension caused by increased gastric fill. Consistent with this hypothesis, animal 217 studies have demonstrated that increased gastric distension, via an intra-gastric balloon, reduced ad218 libitum energy intake [10], likely via vagal nerve stimulation [11]. The water preload ingested in the 219 present study increased perceptions of stomach fullness from 16 (1-45) mm to 55 (2-75) mm, 220 suggesting the volume was sufficient to produce, at least some, gastric distension. Water empties 221 rapidly from the stomach, with a half emptying time of approximately 10 min [18]. Most subjects 222 remained in the feeding booth for $<10 \mathrm{~min}$ and thus a relatively large volume of water would be 223 present in the stomach throughout feeding, resulting in increased feelings of gastric distention during 224 feeding. Whilst ad-libitum energy intake appears to be suppressed at a single meal, future studies 225 should extend these findings by examining whether this reduction in energy intake during feeding 226 influences appetite perceptions in the hours after eating or energy intake at subsequent feeding 227 opportunities. Furthermore, water intake was reduced during feeding following the water preload. 228 Whilst we only provided water with the ad-libitum meal, in free living situations energy containing 
drinks might be consumed with a meal and if peri-prandial fluid intake is reduced, energy intake through energy containing drinks might also be reduced.

In a cross-sectional study Popkin et al [20] reported that those that consume water have a lower daily energy intake ( $200 \mathrm{kcal} /$ day) than those that don't consume water [20]. Stookey et al. [21] conducted secondary analyses of a weight loss intervention trial and demonstrated that among dieters with a low baseline water intake, increasing water to $>1$ litre per day was associated with increased weight loss. These studies suggest that daily water intake appears to be important for weight management, but only one study has tested the chronic effects of pre-meal water preloads on weight loss [5]. Dennis et al. [5] examined the effect of ingesting a $500 \mathrm{ml}$ water preload $30 \mathrm{~min}$ before breakfast, lunch and dinner in overweight and obese middle aged and older adults consuming a prescribed hypocaloric diet for 12 weeks. Compared to a no preload control group, the water preload group lost $44 \%$ more weight $(\sim 2 \mathrm{~kg})$. The present study suggests that immediate pre-meal water ingestion might be a strategy that could help facilitate weight management among younger adults.

In conclusion, the results of the present study demonstrate that consuming a $568 \mathrm{ml}$ water preload immediately before a meal reduced perceptions of hunger, increased perceptions of fullness and satisfaction and resulted in a $22 \%$ reduction in ad-libitum energy intake in young lean males. Future studies should investigate the acute energy intake effects of immediate pre-meal water ingestion in lean young females and overweight/ obese young males and females, as well as examining the chronic weight loss effects of such a dietary strategy.

\section{Conflict of interest}

253 The authors declare they have no conflict of interest. 
1. Health \& Social Care Information Centre (2014) Statistics on obesity, physical activity and diet: England. Available at http://www. hscic.gov.uk.

2. Anderson GH, Moore SE (2004) Dietary proteins in the regulation of food intake and body weight in humans. J Nutr 134:974S-979S.

3. Bowen J, Noakes M, Trenerry C, Clifton PM (2006) Energy intake, ghrelin, and cholecystokinin after different carbohydrate and protein preloads in overweight men. J Clin Endocrinol Metab 91:1477-1483.

4. Bertenshaw EJ Lluch A, Yeomans MR (2008) Satiating effects of protein but not carbohydrate consumed in a between-meal beverage context. Physiol Behav 93:427-436.

5. Dennis EA, Dengo AL, Comber DL, Flack KD, Savla J, Davy KP, Davy BM (2010) Water consumption increases weight loss during a hypocaloric diet intervention in Middle-aged and older adults. Obesity 18:300-307.

7. Rolls BJ, Kim S, Fedoroff IC (1990) Effects of drinks sweetened with sucrose or aspartame

6. Muckelbauer R, Sarganas G, Grüneis A, Muller-Nordhorn J (2013) Association between water consumption and body weight outcomes: A systematic review. Am J Clin Nutr 98:282-299. on hunger, thirst and food intake in men. Physiol Behav 48:19-26.

8. Van Walleghen EL, Orr JS, Gentile CL, Davy BM (2007) Pre-meal water consumption reduces meal energy intake in older but not younger subjects. Obesity 15:93-99.

9. Davy BM, Dennis EA, Dengo AL, Wilson KL, Davy KP (2008) Water consumption reduces energy intake at a breakfast meal in obese older adults. J Am Diet Assoc 108:1236-1239. food intake in dogs. Am J Physiol 169:229-235. 
11. Paintal A (1954) A study of gastric stretch receptors. their role in the peripheral mechanism of satiation of hunger and thirst. J Physiol 126:255-270.

12. Clarkston WK, Pantano MM, Morley JE, Horowitz M, Littlefield JM, Burton FR (1997) Evidence for the anorexia of aging: Gastrointestinal transit and hunger in healthy elderly vs. young adults. Am J Physiol 272:R243-R248.

13. Stunkard AJ, Messick S (1985) The three-factor eating questionnaire to measure dietary restraint, disinhibition and hunger. J Psychosom Res 29:71-83.

14. Faul F, Erdfield E, Buchner A, Lang AG (2009) Statistical power analyses using G*Power 3.1: Tests for correlation and regression analyses. Behav Res Methods 41:1149-1160

16. Flint A, Raben A, Blundell JE, Astrup A (2000). Reproducibility, power and validity of visual analogue scales in assessment of appetite sensations in single test meal studies. Int $\mathrm{J}$ Obes Relat Metab Disord 24:38-48.

17. Calbet JA, MacLean DA (1997) Role of caloric content on gastric emptying in humans. J Physiol 498:553-559.

18. Vist GE, Maughan RJ (1994) Gastric emptying of ingested solutions in man: effect of beverage glucose concentration. Med Sci Sports Exerc 26:1269-1273.

19. Rolls BJ, McDermott TM (1991) Effects of age on sensory-specific satiety. Am J Clin Nutr 54:988-996.

20. Popkin BM, Barclay DV, Nielsen SJ (2005) Water and food consumption patterns of U.S. adults from 1999 to 2001. Obes Res 13:2146-2152. 

3022. 
380

381

382

383

384

385

386

387

388

389

390

391

392

393

394

395

396

397

398

399

400

401

402

403

404

405

406

407

408

409

410

411

412

413

414

415

416

417

418

419

420

421

422

423

424

425

426

427

428

429
Figure legends

Figure 1. Energy intake (kJ) at an ad-libitum breakfast for each participant immediately after consuming $568 \mathrm{ml}$ water (preload) or no water (control). 
431 Table 1. Subjective feelings of fullness, hunger and satisfaction rated on $100 \mathrm{~mm}$ visual analogue 432 scales with verbal anchors "not at all” and "extremely" at $0 \mathrm{~mm}$ and $100 \mathrm{~mm}$, respectively. Values are 433 median (range).

434

\begin{tabular}{lllll}
\hline & & Pre-trial & Post-Drink & Post-trial \\
\hline Fullness $(\mathrm{mm})$ & Control & $16(1-43)$ & $16(1-43)$ & $91(74-100)^{*}$ \\
& Preload & $16(1-45)$ & $55(2-75)^{* \#}$ & $88(67-100)^{*}$ \\
Hunger $(\mathrm{mm})$ & Control & $74(23-98)$ & $74(23-98)$ & $5(1-17)^{*}$ \\
& Preload & $77(59-97)$ & $63(27-91)^{* \#}$ & $7(2-19)^{*}$ \\
Satisfaction $(\mathrm{mm})$ & Control & $21(4-46)$ & $21(4-46)$ & $86(54-96)^{*}$ \\
& Preload & $22(5-47)$ & $31(12-67)^{* \#}$ & $84(62-99) *$
\end{tabular}


$464 \quad$ Figure 1

465

466

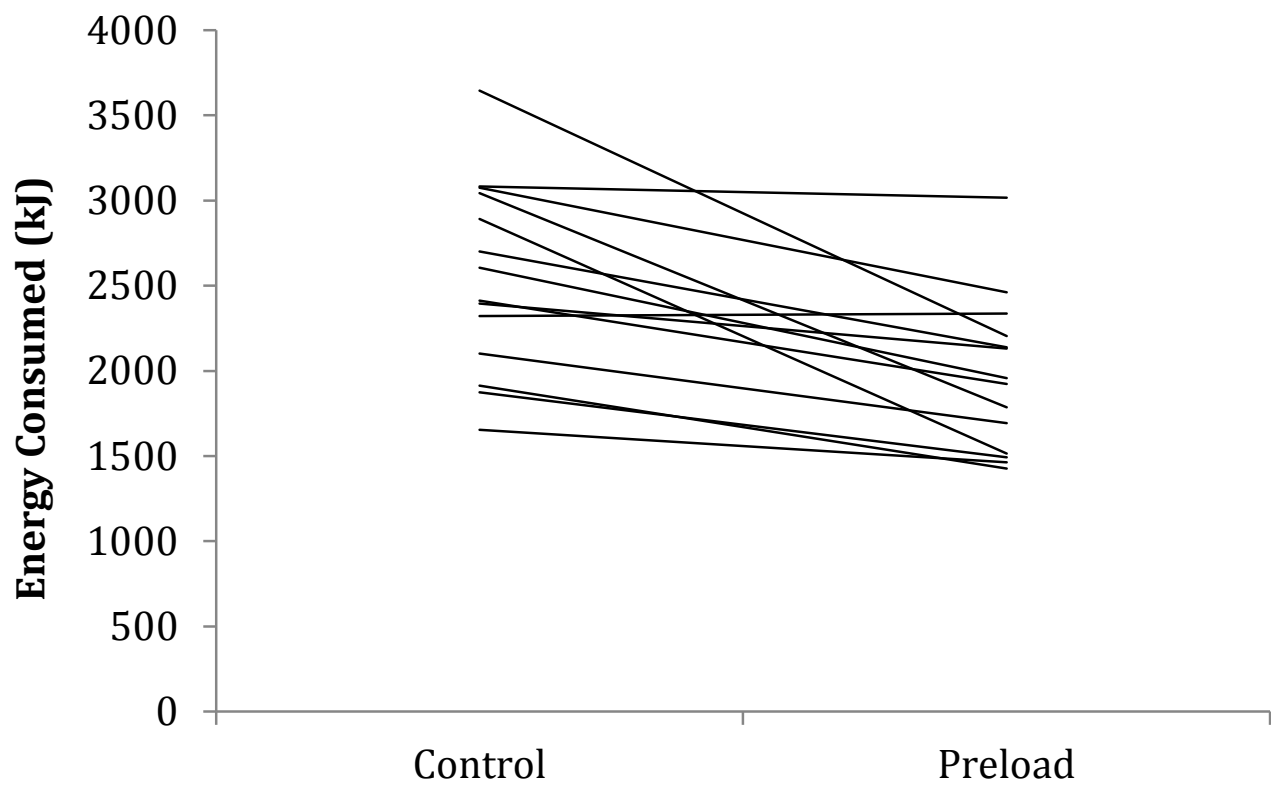

467

468 